\title{
A SOCIOLOGIA NA EDUCAÇÃO SUPERIOR: SENTIDOS PRODUZIDOS NAS NARRATIVAS DE ESTUDANTES DE ODONTOLOGIA DA UNIVERSIDADE ESTADUAL DE MARINGÁ
}

\begin{abstract}
RESUMO: Este artigo integra o rol dos estudos sobre o ensino de Sociologia na Educação Superior. Tem como objetivo apreender os sentidos e a importância que os alunos da graduação em Odontologia da Universidade Estadual de Maringá (UEM) atribuem à disciplina de Sociologia na sua formação profissional e relacioná-los com os discursos legais e formais do curso e com as competências da sociologia para a Educação Superior. É uma pesquisa de abordagem qualitativa. Os resultados do estudo evidenciam que a importância que os estudantes atribuem à sociologia está em consonância com as competências da disciplina e com as questões legais e formais do curso de graduação em Odontologia. Contudo, não se trata de uma reprodução de discursos, mas de sujeitos que falam de sua experiência concreta com a disciplina, de modo que os conteúdos sociológicos passam a produzir sentido para as suas vidas e para o exercício da profissão.
\end{abstract}

Palavras-chave: Educação Superior, Ensino de Sociologia, Curso de Odontologia.

\section{THE SOCIOLOGY IN HIGHER EDUCATION: MEANING PRODUCED IN NARRATIVES OF DENTISTRY STUDENTS AT THE STATE UNIVERSITY OF MARINGÁ}

\begin{abstract}
This article integrates the list of studies on teaching Sociology in higher education. It has the objective of how to understand the significance and importance that undergraduate students in Dentistry at the State University of Maringá (UEM) attribute to the discipline of Sociology in their professional training and to relate them to legal discourses and formal courses, along with the competencies of the sociology for Higher Education. The research is qualitative. The results show that the importance the students gave to sociology is in line with the skills of the discipline and the legal and formal questions of the undergraduate degree course in dentistry. However, it is not a reproduction of discourses, but subjects that speak of their concrete experience with the discipline, so that the sociological content starts to produce meaning for their lives and in the exercise of their profession.
\end{abstract}

Keywords: Higher education, Sociology teaching, Dentistry degree course.

\footnotetext{
${ }^{1}$ Programa de Pós-Graduação em Educação, da Universidade do Oeste de Santa Catarina (UNOESC). Joaçaba, SC, Brasil.

*Doutora em Sociologia pela Universidade Federal do Paraná (UFPR ). Professora e pesquisadora no Programa de PósGraduação em Educação, da Universidade do Oeste de Santa Catarina (UNOESC). Joaçaba, SC, Brasil. <nfurlin@yahoo.com.br>
} 


\section{SOCIOLOGÍA EN LA EDUCACIÓN SUPERIOR: SENTIDOS PRODUCIDOS EN LAS NARRATIVAS DE ESTUDIANTES DE ODONTOLOGÍA DE LA UNIVERSIDAD ESTATAL DE MARINGÁ}

RESÚMEN: Este artículo integra los estudios sobre la enseñanza de la sociología en la educación superior. Tiene como objetivo comprender los significados y la importancia que los estudiantes de pregrado en Odontología de la Universidad Estatal de Maringá (UEM) atribuyen a la disciplina de la sociología en su formación profesional y relacionarlos con los discursos legales y formales del curso y con las competencias de la sociología para la Educación Superior. Es una investigación cualitativa. Los resultados del estudio muestran que la importancia que los estudiantes otorgan a la sociología está en consonancia con las habilidades de la disciplina y con los discursos legales y formales del curso de pregrado en Odontología. Sin embargo, esto no es una reproducción de discursos, sino sujetos que hablan de su experiencia concreta con la disciplina, de modo que los contenidos sociológicos comienzan a producir significado para sus vidas y para el ejercicio de la profesión.

Palabras clave: Educación Superior, Enseñanza de Sociología, Curso de Odontología

\section{INTRODUÇÃO}

As pesquisas sobre o ensino de Sociologia têm sido mais recorrentes no universo da Educação Básica, onde é possível encontrar uma vasta literatura. Já na Educação Superior os estudos sobre a Sociologia é ainda um campo recente. Há poucos trabalhos que refletem acerca dos limites, desafios e potencialidades da sociologia para a formação de profissionais de diferentes áreas acadêmicas. Isso justifica a importância deste estudo focado em compreender os sentidos que os estudantes de Odontologia da Universidade Estadual de Maringá (UEM) atribuem à Sociologia e a relação desses sentidos com as questões legais do curso e com as competências da disciplina para a Educação Superior.

A Sociologia é uma ciência relativamente jovem. Surgiu no século XIX em um contexto de mudanças ocasionadas pelas revoluções francesa e industrial, ocorridas na sociedade europeia. Sua primeira função foi explicar e compreender as condições de emergência dos novos fenômenos e as transformações socioculturais que decorreram dessas duas grandes revoluções. Na sua origem, a Sociologia buscou compreender a nova sociedade fundamentada em três matrizes teóricas: funcionalista, marxista e weberiana, cujas vertentes deram origem a outras abordagens teóricas que foram surgindo ao longo do século XX. Contudo, vale recordar que essa ciência se consolidou em meio a tensões, ambiguidades, falta de consensos e disputas acerca da natureza de seu objeto, da diversidade de concepções teóricas e de seu caráter crítico. E, segundo Anthony Giddens (1984), isso não significa fraqueza, mas pontos que fortalecem ainda mais a especificidade da contribuição desta ciência, no rol das demais, sobretudo por ter de lidar com fenômenos sociais mutáveis, que diferem dos fenômenos naturais, regidos por leis imutáveis. Já para o sociólogo francês Bernard Lahire (2014), os conflitos que envolvem a diversidade teórica e metodológica não é absolutamente um sintoma de não cientificidade, mas o sinal de um funcionamento "normal" das pesquisas científicas e, como em todas as ciências, os conflitos entre correntes de pensamento é expressão de uma saúde crítica da própria ciência e não impedem a existência de um campo de referências e de aquisições teórico -metodológicas de quem exerce a profissão de investigador.

Nesse sentido, de acordo com Otávio Ianni (1999), a Sociologia é considerada uma ciência complexa, pelas suas distintas vertentes, que continua tendo grande importância por ser uma forma de autoconsciência científica da realidade social, que "expressa o entendimento que a sociedade, no seu todo ou em seus segmentos mais importantes, desenvolve a propósito de sua organização e seu funcionamento, refletindo o modo pelo qual ela se produz e reproduz, se forma e se transforma." 
(IANNI, 1999, p. 15). Lahire (2014) defende que a Sociologia tem um papel crucial para a vida coletiva e para a formação de pessoas cidadãs em sociedades democráticas e argumenta em prol da necessidade do ensino desta ciência desde o mais cedo possível, uma vez que ela apresenta o mundo social a partir de um pensamento menos mágico e naturalizado e mais científico.

Enquanto nos países latino-americanos a Sociologia foi introduzida no Ensino Superior por meio dos cursos de Direito, no Brasil, foi introduzida, inicialmente, na grade curricular do "Ensino Secundário", em especial, nas Escolas Normais, no final do século XIX, quase concomitante ao seu aparecimento no Ensino Superior, nos cursos voltados para a formação de educadores para o ensino básico. Nesse contexto, o objetivo da sociologia, sobretudo no ensino superior, era o de reproduzir a nova visão de mundo no país que se havia constituído em uma república, e questionar as ideias que davam sustentação à antiga ordem social (REGO, 2005).

$\mathrm{Na}$ década de 1930, o país passava por transformações sociais, políticas, econômicas e culturais e as elites intelectuais consideraram ser necessária uma análise sociológica, em vista de reorganizar a sociedade e promover o progresso e a integração nacional. Entre os anos de 1933 a 1935, surgiram importantes Instituições de Ensino Superior (IES), como a Escola Livre de Sociologia e Política de São Paulo, a Universidade de São Paulo e a Universidade do Distrito Federal (RJ). Nessas universidades foram criados os cursos de Ciências Sociais de modo que a disciplina de Sociologia começou a ser sistematizada e convertida aos padrões acadêmicos. Os intelectuais construíram um projeto político-educacional com base nos interesses republicanos e liberais, transformando a Universidade em instrumento de formação das elites dirigentes para o processo de "modernização" do país.

Nesse cenário, "o ensino da Sociologia correspondia aos ideais de expansão da cultura científica, de civilidade, do patriotismo e dos padrões de cultura erudita" (REGO, 2005, p. 11). A intervenção na formação das novas gerações visava oferecer técnicas teóricas e racionais que fossem capazes de solucionar os problemas sociais do país, sem questionar ou gerar conflitos sociais. Para Florestan Fernandes (1977), essa perspectiva transformou as Ciências Sociais em técnicas e instrumentos de controle, com a finalidade de conter os conflitos sociais. A abordagem sociológica predominante era a funcionalista, pautada nos ideais positivistas.

Alguns sociólogos foram, aos poucos, adotando a vertente crítica da Sociologia, orientando seus estudos para os setores sociais esquecidos e oprimidos da sociedade. O contexto mais democrático da política nacional, durante a década de 1950 e parte dos anos de 1960, permitiu ampliar a presença da disciplina de Sociologia em diferentes cursos de nível superior ${ }^{3}$. Isso foi possível graças à expansão das Faculdades de Filosofia, Ciências e Letras.

Durante a ditadura, as abordagens da sociologia crítica foram alvos de fortes embates políticos. Muitos professores e pesquisadores universitários foram afastados do seu trabalho e outros expulsos do país. Com o processo de redemocratização do país, a partir dos anos de 1980, houve a abertura de novos cursos de Ciências Sociais e a perspectiva da sociologia crítica passou a ganhar maior status na academia, ao lado de outras correntes sociológicas (REGO, 2005). Concomitante ao processo de expansão do Ensino Superior, a partir da década de 1990 houve a ampliação do ensino de Sociologia em diferentes cursos de graduação do Ensino Superior, tanto na esfera pública quanto na privada. Contudo, essa disciplina, em geral, tem sido ofertada na modalidade de Introdução à Sociologia ou

\footnotetext{
${ }^{2}$ Segundo Nise Jinquins (2007), a sociologia foi proposta como disciplina obrigatória na grade curricular do ensino secundário, pela primeira vez, em 1882. Contudo, o ensino de sociologia no currículo escolar apresenta uma trajetória intermitente. Sobre isso ver Amurabi de Oliveira (2013), já que não é nosso objetivo abordar a história da sociologia na educação básica, uma vez que sobre isso se tem uma vasta literatura, com resultados de estudos realizados por muitos pesquisadores.

${ }^{3}$ Ela era mais recorrente nos cursos de Pedagogia, Ciências Sociais e Direito. 
Sociologia aplicada às especializações profissionais, com uma carga horária reduzida, implicando, muitas vezes, processos de instrumentalização e de disputas departamentais (BRUNETTA; AMARAL, 2017).

Observando tais considerações indaga-se: como os estudantes percebem o ensino de Sociologia nos diferentes cursos? Avaliam como uma disciplina significativa para sua carreira profissional? $\mathrm{Na}$ impossibilidade de uma vasta pesquisa sobre tal questão, neste artigo, optamos por um curso da área da saúde, sobretudo, porque nos últimos anos há a preocupação de um olhar interdisciplinar para o processo saúde-doença, para o qual a Sociologia tem trazido importante contribuição. Trata-se de um estudo situado que pretende compreender quais os sentidos e a importância que os/as estudantes do Curso de Odontologia atribuem à Sociologia em sua formação profissional. Até que ponto esses sentidos se aproximam dos aspectos assinalados pelas Diretrizes Curriculares Nacionais (DCNs), com o Projeto Pedagógico do Curso de Graduação em Odontologia (PPC) e com as competências do ensino de Sociologia, na Educação Superior, especificamente, quando aplicada à área da saúde?

Nesse sentido, o presente artigo tem como objetivo apreender os sentidos e a importância que os alunos da graduação em Odontologia da UEM atribuem à disciplina de Sociologia na sua formação profissional e relacioná-los com os discursos legais e formais do curso e com as competências da disciplina para a Educação Superior. Não se pretende fazer grandes generalizações, mas mostrar como os conteúdos de uma disciplina, ao interagirem com a capacidade reflexiva dos estudantes, em um contexto situado, produzem efeitos ou sentidos que são objetivados em narrativas, de modo que as competências da disciplina acabam se materializando nas experiências concretas desses estudantes. Essa compreensão situada pode, sim, ampliar o olhar e generalizar os efeitos da disciplina de Sociologia e sua importância para além do curso de Odontologia.

Acreditamos que se trata de um estudo relevante, já que se encontram poucos estudos que problematizam a importância da disciplina de Sociologia na formação profissional em nível superior. Além disso, em tempos que a educação parece se voltar aos interesses do mercado neoliberal e ao tecnicismo profissional, evidenciar os significados que os estudantes atribuem a disciplinas da área de humanas e sociais em sua formação profissional pode trazer elementos significativos que problematizam uma realidade em que a carga horária dessas disciplinas, na matriz curricular de algumas áreas, vem sendo reduzida por uma compreensão de que tal saber não seja tão necessário.

\section{PRESSUPOSTOS TEÓRICO-METODOLÓGICOS}

Este estudo se fundamenta em uma abordagem qualitativa, a qual permite compreender os fenômenos a partir dos sujeitos, de suas experiências e vivências. Com isso, torna-se possível incorporar o significado e intenção aos atos, às relações e às estruturas sociais, sendo essas últimas tomadas, tanto no seu advento, na sua transformação, quanto nas construções humanas significativas (MINAYO, 2000). Trata-se de um estudo baseado em pesquisa bibliográfica, documental (DCNs e PPC) e análise interpretativa de 38 narrativas de estudantes do segundo ano do Curso de Odontologia da $\mathrm{UEM}^{4}$, sendo que 28 eram do sexo feminino $(76,7 \%)$ e 10 do sexo masculino $(26,3 \%)^{5}$. Essas narrativas foram colhidas de um trabalho acadêmico de conclusão de disciplina (memorial reflexivo) elaborado para fins de avaliação do processo ensino-aprendizagem. Detemo-nos nas considerações finais do trabalho onde

\footnotetext{
${ }^{4}$ Também foi agendada conversa com o coordenador da disciplina saúde coletiva, visando clarear elementos da estrutura curricular do curso.

${ }^{5}$ Esses dados vêm corroborar com os estudos que mostram a existência de um processo de feminização das profissões da saúde, como a medicina e a odontologia, que historicamente foram consideradas masculinas. Segundo Matos et al (2013), nas faixas etárias mais jovens, as mulheres são a maioria na carreira profissional de odontologia em 25 dos 27 estados do Brasil e, em 2013, eram 56\% do total dos profissionais, dados que acompanham o ingresso progressivo das mulheres brasileiras no ensino superior.
} 
os/as estudantes elaboraram uma reflexão pessoal a respeito da importância da disciplina de Sociologia na sua formação profissional, em que ela contribuiu e o que fez suscitar de novo ${ }^{6}$.

Consideramos que esse recorte metodológico, em que se analisam narrativas de um grupo de estudantes, com uma posição situada dentro do conjunto dos cursos de nível superior, atende os objetivos do estudo, conforme já mencionado, uma vez que o material utilizado foi produzido pelos estudantes unicamente para fins de avaliação da disciplina, livre de qualquer interesse induzido para a pesquisa. Ao tomar conhecimento do material considerou-se significativo fazer um estudo aproximando os sentidos narrados pelos estudantes com os discursos legais e formais da disciplina, buscando evidenciar o grau de aproximação e como os conteúdos sociológicos podem produzir efeitos na visão dos estudantes, de modo que os objetivos da disciplina se materializam na relação interativa com os estudantes, que se produzem sujeitos do próprio discurso de sentido.

Para o processo de análise, as narrativas reflexivas foram recortadas por categorias temáticas e agrupadas em unidades de sentido, de modo que permitisse verificar as incidências em relação à importância que os/as estudantes atribuíam à disciplina da Sociologia. Em um segundo momento, selecionamos fragmentos das narrativas mais representativas para refletir sobre determinados temas, sentidos e desafios, tendo como parâmetro de análise as DCNs, o PPC e as competências atribuídas à Sociologia Geral e aplicadas à saúde.

Adotamos a perspectiva da interpretação hermenêutica, segundo os pressupostos teóricos de Minayo (2003), para compreender os sentidos expostos nas narrativas. De acordo com a autora, o "compreender implica a possibilidade de interpretar, de estabelecer relações e extrair conclusões em toda a direção.” (MINAYO, 2003, p. 92). Nesse processo, a autora alerta que

o investigador não deve buscar nos textos/entrevistas uma verdade essencialista, mas o sentido que quis expressar quem os emitiu. Assim, o investigador só estará em condições de compreender o conteúdo significativo de qualquer documento/ entrevista se fizer o movimento de tornar presente, na interpretação, as razões do autor. (MINAYO, 2003, p. 98).

Por meio das narrativas de estudantes, buscamos compreender os sentidos que eles atribuem à Sociologia, desde as suas experiências de interação com ela e com as informações que possuem sobre as orientações e princípios que regem a formação profissional do Cirurgião-dentista. A perspectiva hermenêutica desloca o pesquisador da posição de protagonista da verdade científica, para um olhar que considera a posição relacional entre os sujeitos. Uma relação que é muito mais que a simples aproximação com as narrativas, mas de deixar-se tocar pelos sentidos produzidos nas narrativas, problematizando-as por meio de um olhar crítico e teórico, de modo que as conclusões de um estudo é apenas uma de tantas outras possibilidades que poderão emergir a partir de outros olhares teórico-metodológicos (MINAYO, 2003).

Nessa perspectiva, os/as estudantes participaram como sujeitos da produção do conhecimento, por meio das narrativas que foram analisadas pela investigadora. O educador Alan Peshkin (1993, p. 24) já dizia que "o caminho de nosso saber está atrelado ao conteúdo de nosso conhecimento e às nossas relações com os participantes da pesquisa”. Trata-se de um saber produzido em uma relação de intersubjetividade, como Minayo (2003) ressalta na teoria hermenêutica, uma vez que essa metodologia desloca o pesquisador da posição de protagonista da verdade científica para um olhar que considera a posição relacional entre os sujeitos. Uma relação que é muito mais que a simples aproximação com os conteúdos das narrativas dos estudantes, porque se trata de uma postura em que a pesquisadora se deixa tocar por essas narrativas, problematizando-as por meio de um olhar relacional, crítico e teórico ${ }^{7}$.

\footnotetext{
${ }^{6}$ Vale ressaltar que o memorial reflexivo, realizado pelos estudantes, não foi para fins de pesquisa, mas unicamente para avaliação da disciplina. Ao tomar contato com o material, a pesquisadora considerou importante fazer uma análise dos sentidos que os/as estudantes atribuíram à disciplina, dentro do rigor metodológico que se exige para um trabalho científico. A utilização desse material teve o consentimento dos/as estudantes, por meio de um documento assinado.

${ }^{7}$ Segundo o exposto neste parágrafo, a relação próxima e intersubjetiva com os acadêmicos, professora/estudantes, não inviabiliza a cientificidade da pesquisa, uma vez que ao se focar na ação interpretativa dos sentidos dos conteúdos das narrativas dos estudantes (que participam como sujeitos do conhecimento), na relação com os documentos legais e à luz de pressupostos Educação em Revista|Belo Horizonte|v.36|e219614|2020
} 
Neste estudo, os/as estudantes são considerados sujeitos que não se reduzem às suas capacidades narrativas, mas caracterizados pela sua reflexibilidade que vai além do pensamento emitido, porque permite analisar outros possíveis que estão para se inventar. Um sujeito caracterizado por suas capacidades de ação, de criação, de decisão, de realização, isto é, de transformação do mundo no qual ele vive e, por isso mesmo, de transformação de sua existência própria (GAULEJAC, 2004/2005).

A compreensão hermenêutica dos conteúdos das narrativas dos/as estudantes é realizada à luz dos pressupostos teóricos que embasam os documentos legais ${ }^{8}$, no que diz respeito às competências da disciplina de Sociologia para o Ensino Superior e para a área da saúde e das concepções de Oliveira e Costa (2007), Lahire (2014) e Giddens (1984) sobre a especificidade da sociologia como ciência e de sua particularidade na formação acadêmica.

\section{COMPETÊNCIAS DA DISCIPLINA DE SOCIOLOGIA PARA O ENSINO SUPERIOR}

O sociólogo Anthony Giddens (1984) argumenta que a função da Sociologia não se restringe a descrever e explicar os fenômenos sociais, mas compreendê-los de maneira crítica. Considera que o pensamento sociológico, como um empreendimento crítico, precisa estar estruturado em torno das três dimensões da imaginação sociológica: a) na sensibilidade histórica em relação aos modos de vida do passado e de suas diferenças no presente; b) na perspectiva antropológica que permite nos afastar do etnocentrismo e do evolucionismo e apreciar a diversidade dos modos humanos que tem nos sucedido no mundo; c) na capacidade de pensar as possibilidades futuras, não arrastados por forças inevitáveis, como as leis naturais, mas conscientes das alternativas que potencialmente se apresentam nas dinâmicas sociais. Para Giddens, é nessa terceira dimensão que a imaginação sociológica se une à tarefa da Sociologia ao contribuir para a crítica das formas existentes da sociedade. Como teoria crítica, a sociologia não toma o mundo social, com um dado, mas problematiza e desnaturaliza as realidades, perguntando sobre as mudanças possíveis.

Nessa perspectiva, o ensino de Sociologia, como uma ciência das humanidades, ganha importância pela sua especificidade enquanto uma ciência que possibilita desnaturalizar e problematizar a realidade social, compreendendo-a de maneira crítica e reflexiva. Essa competência, a ser desenvolvida nos estudantes, em parte aparece inscrita nas orientações legais e formais para o Ensino Superior, cujo discurso enfatiza a necessidade de uma formação que prepare os jovens para o mercado de trabalho, para o pensamento científico e reflexivo e para o exercício da cidadania (BRASIL, 1997, 2002) ${ }^{9}$. Nessa mesma direção, a Conferência Mundial sobre Educação Superior da UNESCO, realizada em 1998, enfatiza que uma das missões da Educação Superior é a de "contribuir para o desenvolvimento sustentável e o melhoramento da sociedade como um todo", formando pessoas "altamente qualificadas, cidadãs e cidadãos responsáveis que se tornam capazes de atender às necessidades de todos os aspectos da atividade humana." Tal concepção se encontra também no Parecer CNE/CES n. 777/1997, que determina que as diretrizes curriculares dos cursos de graduação devem "incluir dimensões éticas e humanísticas, desenvolvendo no aluno atitudes e valores orientados para a cidadania." (BRASIL, 1997, p. 1).

Segundo Brunetta e Amaral (2017), a disciplina de Sociologia no Ensino Superior, fora do curso de Ciências Sociais, foi legitimada nas matrizes curriculares, no âmbito legal e formal, por ter a potencialidade de desenvolver nos estudantes os valores relacionados à cidadania. Contudo, a ideia de cidadania não é problematizada nos documentos, de modo que a política curricular acaba permitindo que ela orbite no paradigma liberal, reduzida à compreensão de participação social e política.

Considera-se que o papel da Sociologia não é apenas formar para a cidadania, cuja competência deveria ser transversal a todas as disciplinas acadêmicas, mas sim fomentar o pensamento crítico e reflexivo sobre os fenômenos sociais, estabelecendo relações com as diferentes dimensões da vida social. Para Oliveira e Costa (2007), a Sociologia deve levar o estudante a pensar a realidade social

teóricos, produz-se o afastamento necessário e a criticidade reflexiva que garantem a objetividade e cientificidade do estudo. Nesse caso, a vigilância necessária e dada pela metodologia assumida.

${ }^{8}$ Diretrizes Curriculares Nacionais (DCNs) e Projeto Pedagógico do Curso de Graduação em Odontologia (PPC).

${ }^{9}$ Conforme orientações das DCNs, Parecer CNE/CES n. 777/1997, de 3 de fevereiro de 1997 e Resolução CNE/CES n. 3 , de 19 de fevereiro de 2002 
da qual faz parte, desenvolvendo a consciência de que toda sociedade é uma construção histórica e não uma fatalidade regida por "leis naturais", podendo ser construída e reconstruída segundo as necessidades dos grupos e sujeitos ou atores sociais. Desse modo, o ensino de Sociologia atrela-se a seu próprio caráter reflexivo e crítico, tão necessário para a compreensão do mundo moderno, em suas relações com as diferentes áreas de saber acadêmico.

Para Lahire (2014), a presença da Sociologia em inúmeros cursos universitários ou profissionais, bem como a sua introdução no Ensino Médio tem sido importante porque se trata de uma ciência que atua na direção de uma relação mais racional sobre os fenômenos sociais ou de um conhecimento científico da realidade social, que possibilita sair progressivamente de uma visão subjetiva, emocional e parcial do mundo social. Assim, Lahire argumenta em favor do ensino da Sociologia desde as séries iniciais como uma ferramenta que permite construir uma resposta adequada às exigências modernas de formação escolar dos cidadãos nas sociedades democráticas.

\section{A SOCIOLOGIA NO CAMPO DA SAÚDE}

A Sociologia da Saúde é um dos ramos da Sociologia Geral que estuda os fenômenos sociais que envolvem o processo saúde-doença. Pauta-se na compreensão da saúde como um fenômeno social, resultado das interações humanas e produto da vida em sociedade. A doença, nessa perspectiva, é considerada uma realidade construída em contextos históricos-sociais precisos (MARTINS; FONTES, 2008). Vale ressaltar, que a saúde como objeto de estudo da Sociologia é algo muito recente, consolidando-se nas últimas décadas do século XX. No Brasil, o tema da saúde entrou no campo dos estudos sociológicos nos anos de 1970, cujo debate se tornou importante para a formação dos profissionais da área, por contribuir com a ampliação da compreensão do processo saúde-doença.

De acordo com Martins e Fontes (2008), o diálogo entre Sociologia e Ciências da Saúde (Medicina Social, Epidemiologia e Saúde Coletiva) tem permitido avançar nos estudos sobre saúde em uma perspectiva interdisciplinar e ampliar a compreensão do conceito de saúde, considerando as dimensões culturais, sociais, políticas afetivas e ambientais. Tal diálogo foi fundamental para compreender que o isolamento e o fechamento das áreas do conhecimento sobre si mesmas podem levar a um reducionismo que se torna prejudicial ao conhecimento da realidade e às práticas sociais. Com efeito, durante muitos anos, nas ciências médicas esse reducionismo teve conexão com um conceito de saúde e de doença bastante restrito, explicado somente a partir de fatores biológicos e físicos e ao tratamento mais curativo que preventivo. Contudo, o modelo biomédico começou a ser questionado a partir da segunda metade do século XX, quando houve uma aproximação maior das Ciências Sociais com o objeto das ciências médicas (BARROS MIOTTO; MARCELO, 2009).

A contribuição das Ciências Sociais, inclua-se aqui a Sociologia, foi fundamental para as mudanças nas práticas de saúde e para o rompimento com o modelo biomédico. No Brasil, nos anos de 1980, isso se refletiu no movimento contra hegemônico, que desembocou no projeto da Reforma Sanitária e na criação da Associação Brasileira de Pós-graduação em Saúde Coletiva. Essa associação exerceu um papel importante no processo de sistematização das propostas traçadas pela III Conferência Nacional de Saúde, em vista da mudança do modelo de saúde. Todo esse esforço culminou no projeto reformador da saúde, pautado em um conceito mais amplo, que foi assumido com a criação do Sistema Único da Saúde (SUS), em $1988^{10}$ (BARROS MIOTTOT; MARCELO, 2009).

Segundo Barros e Nunes (2009), o olhar das Ciências Sociais e o seu diálogo com as Ciências da Saúde promove a humanização no cuidado e nas relações de trabalho; mostra a importância de um trabalho multidisciplinar e interdisciplinar; permite considerar a dimensão social no processo saúdedoença; educa para o respeito às diferenças e a diversidades de pacientes e possibilita o desenvolvimento do pensamento holístico e do pensamento crítico.

Considerando tais questões e o novo conceito de saúde, que passou a fundamentar as práticas do SUS, a partir da década de 1990, a disciplina de Sociologia ou das Ciências Sociais foi incluída no currículo de diversos cursos da área da saúde, tendo em vista a sua contribuição para a formação de

\footnotetext{
${ }^{10}$ Vale lembrar que a grande conquista do Movimento de Reforma Sanitária foi garantir na Constituição Federal a saúde como um direito de todos e um dever do Estado.
} 
profissionais com uma visão interdisciplinar do processo saúde-doença. Vale lembrar que a inserção da Sociologia nas diferentes áreas do conhecimento científico fomenta uma formação crítica e cidadã do profissional, fundada em valores democráticos, que vai além do tecnicismo, como é a intenção das DCNs. Na área da saúde, o ensino de Sociologia é uma das ciências que tem contribuído para a crítica e a superação do modelo biomédico do processo saúde-doença, compreendendo-o como um fenômeno multicausal, profundamente marcado pelas influências dos contextos social, econômico, político, afetivo e ambiental (BARROS MIOTTO; MARCELO, 2009).

Portanto, este trabalho tem sua relevância por buscar compreender, a partir da visão dos estudantes, qual é a importância da disciplina de Sociologia na formação de profissionais de uma das áreas da saúde, que aqui se trata do Curso de Odontologia da Universidade Estadual de Maringá (UEM).

\section{A PERSPECTIVA SOCIOLÓGICA E HUMANISTA NO CURSO DE ODONTOLOGIA: QUESTÕES LEGAIS}

Quando analisamos a Resolução CNE/CES. 2002, sobre as Diretrizes Curriculares Nacionais do Curso de Graduação em Odontologia, não é difícil constatar a importância dos conteúdos da Sociologia para a formação de Cirurgiões Dentistas ${ }^{11}$. Observa-se a preocupação com a preparação de profissionais que se adequem ao novo conceito de saúde-doença, que está na base do SUS. As DCNs sugerem que o profissional egresso do Curso de Odontologia tenha

uma formação generalista, humanista, crítica e reflexiva, para atuar em todos os níveis de atenção à saúde, com base no rigor técnico e científico. Capacitado ao exercício de atividades referentes à saúde bucal da população, pautado em princípios éticos, legais e na compreensão da realidade social, cultural e econômica do seu meio, dirigindo sua atuação para a transformação da realidade em benefício da sociedade (BRASIL, 2002, p. 1).

Notam-se, claramente, aspectos que são de competência das Ciências Sociais e Humanas, como a ênfase na necessidade de uma "formação crítica e reflexiva", que "leve o profissional a compreender a realidade social e econômica do seu meio, dirigindo a sua atuação para a transformação da realidade em benefício da sociedade."

Para a formação desse profissional, entre os conteúdos essenciais que devem constar na estrutura curricular do Curso de Graduação em Odontologia, as DCNs sugerem que, além dos voltados à formação técnico-profissional, sejam contemplados também conteúdos da área das Ciências Humanas e Sociais, priorizando os que se referem "às diversas dimensões da relação indivíduo/sociedade, contribuindo para a compreensão dos determinantes sociais, culturais, comportamentais, psicológicos, ecológicos, éticos e legais, nos níveis individual e coletivo, do processo saúde-doença.” (BRASIL, 2002, p. 3). A Resolução CNE/CES n. 3, de 19 de fevereiro de 2002, do MEC, deixa evidente a importância de garantir os conteúdos específicos da Sociologia e a sua aplicação para a área da saúde, no que diz respeito à compreensão ampla do processo saúde-doença e os seus determinantes sociais, como descrevemos anteriormente. A garantia desses conteúdos se articula com o estilo de profissional, que precisa ser formado para responder às novas exigências do SUS. Isso nos reporta diretamente a Oliveira (2012), pois segundo a autora, o currículo é, a um só tempo, uma questão de conhecimento e de identidade. Ou seja, não se refere apenas a que conhecimento se deseja transmitir ou suscitar, mas, também, de saber que tipo de indivíduo se quer formar com determinado conhecimento.

As DCNs estabelecem um conjunto de competências e habilidades que a formação do Cirurgião-Dentista precisa desenvolver nos profissionais egressos, entre as quais, algumas se referem aos conteúdos sociológicos e humanísticos, como se observa a seguir:

[...] exercer sua profissão de forma articulada ao contexto social, entendendo-a como uma forma de participação e contribuição social; atuar multiprofissionalmente, interdisciplinarmente e transdisciplinarmente com extrema produtividade na promoção da saúde baseado na convicção científica, de cidadania e de ética. (BRASIL, 2002, p. 2).

\footnotetext{
11 As DCNs são um conjunto de normas obrigatórias para o curso de graduação que orientam o planejamento curricular dos cursos de graduação, fixadas pelo Conselho Nacional de Educação (CNE). 
Conforme se observa, no fragmento da resolução do CNE/CES, as DCNs orientam que os cursos de graduação não formem somente profissionais na perspectiva técnica, em vista do mercado do trabalho, mas também profissionais cidadãos, éticos, humanos, com capacidade de reflexão crítica e capazes de contribuir de forma ativa para melhorar o entorno social em que atuam. Contudo, isso, em geral, parece continuar sendo uma utopia, porque os conteúdos teóricos de perspectiva crítica, da área das Ciências Sociais e Humanas, ainda ocupam um espaço muito reduzido na estrutura curricular e nem sempre conseguem formar cidadãos éticos e comprometidos com a coletividade social. No atual cenário político, onde se reiteram discursos desfavoráveis à Sociologia e à Filosofia, em que se desqualifica o papel das Ciências Humanas na formação profissional, essa lacuna certamente se ampliará já que a tendência é dar centralidade a uma formação puramente tecnicista, voltada aos interesses do mercado.

\section{O CURSO DE ODONTOLOGIA NA UEM E OS CONTEÚDOS SOCIOLÓGICOS}

O Curso de Odontologia da UEM completou 30 anos em 2018. Foi criado em 1988, juntamente com o curso de medicina, sendo vinculado ao Departamento de Biologia. Em 1991 se transformou em Departamento de Odontologia e adotou um novo modelo pedagógico, isto é, assumiu um currículo multidisciplinar, visando uma formação generalista por meio da integração com as demais áreas do setor de saúde ${ }^{12}$. Isso evidencia que após a criação do SUS, os cursos de graduação na área de Saúde precisaram se adaptar para formar profissionais em consonância com as novas exigências.

A Graduação em Odontologia da UEM está desenhada de acordo com a legislação nacional, uma vez que Projeto Pedagógico do Curso (PPC) assume as proposições das DCNs, aprovadas na Resolução CNE/CES, 2002, quanto ao perfil de formação para o profissional egresso e às competências e habilidades a serem desenvolvidas nos acadêmicos. Trata-se de formar cirurgiões-dentistas com competências, habilidades que atuem com qualidade e resolutividade no Sistema Único de Saúde, em uma compreensão de integralidade da atenção à saúde. Nisso decorre a importância de uma formação generalista, humanista, crítica e reflexiva, cuja contribuição vem das Ciências Humanas e Sociais.

Segundo a filosofia do Projeto Pedagógico do Curso da Graduação em Odontologia da $\mathrm{UEM}^{13}$, faz-se necessário oferecer não apenas uma formação de excelência técnica, mas também adequar o ensino para a realidade epidemiológica e social, visando formar recursos humanos com uma visão generalista da saúde, em sintonia com os princípios do SUS. Uma das finalidades que o PPC estabelece para o Curso de Odontologia é "dar ao aluno uma visão de seu papel na sociedade com conhecimento dos métodos científicos de levantamento das condições sociais e uma formação humanística" (UEM, 2010, p. 10). Enfatiza-se que a formação cultural e humanística é um diferencial que se distingue de uma formação puramente tecnicista. Contudo, quando se analisa a grade curricular da Graduação de Odontologia da UEM, os conteúdos que dizem respeito à formação humanística e cultural ainda são minoritários.

Diferentemente de outros Cursos de Odontologia do Brasil, a organização curricular do curso da UEM é distinta, ou seja, é constituída por 13 Conjuntos Instrucionais ${ }^{14}$, agrupando determinado número de disciplinas que se aproximam de forma integrada e são oferecidas por módulos, durante os cinco anos do curso. Cada módulo inclui determinadas disciplinas que correspondem a Unidades de Ensino. Uma vez que o currículo foi organizado no sentido oposto, priorizando a integração de temas, há a necessidade do fracionamento em disciplinas. As frações são reagrupadas em Células Integradoras de Ensino (UEM, 2010).

De acordo com o coordenador do grupo das disciplinas que formam o Conjunto Instrucional de Saúde Coletiva, do Departamento de Odontologia, essa forma de organização curricular foi idealizada por alguns professores, antes mesmo da criação do Curso de Odontologia na UEM, em 1988, justamente em um contexto em que se estavam discutindo as grandes reformas na área da saúde,

\footnotetext{
12 Para visualizar a organização curricular, consultar UEM: Guia do Estudante de Odontologia, 2010, p. 25. Disponível em: www.dod.uem.br/documentos/ODONTOGuiadoEstudante_2014.doc/at.../file.

13 O atual Projeto Pedagógico do Curso de Graduação foi homologado pela 195/2005-CEP e está disponível no Guia do Estudante de Odontologia e no site do Departamento de Odontologia.

${ }^{14}$ Desses 13 conjuntos instrucionais, 10 são de conteúdos técnicos e somente 03 congregam conteúdos das Ciências Humanas e Sociais, os quais são: saúde coletiva, organizacional e formação humanística e cultural. Educação em Revista|Belo Horizonte|v.36|e219614|2020
} 
que culminaram na criação do SUS. Isso evidencia que um currículo nunca é neutro, mas é construído em sintonia com os fenômenos sociais e culturais de determinada época, como bem nos lembra Michael W. Apple (1997, p. 59):

O currículo nunca é apenas um conjunto neutro de conhecimentos [...] Ele é sempre parte de uma tradição seletiva, resultado da seleção de alguém, da visão de algum grupo acerca do que seja conhecimento legítimo. É produto de tensões, conflitos e concessões culturais, políticas e econômicas que organizam e desorganizam um povo.

A Sociologia Aplicada está inserida no Conjunto Instrucional chamado Saúde Coletiva, que "reúne os conteúdos destinados a identificar os problemas bucais na forma como se manifestam na coletividade, os fatores socioeconômicos e culturais relacionados à saúde e as formas mais adequadas para uma atuação eficiente." (UEM, 2010, p. 23).

As nove disciplinas que compõem o Conjunto Instrucional Saúde Coletiva ${ }^{15}$ são oferecidas no primeiro e segundo ano do curso de graduação, em módulos distintos, compostos por disciplinas que se aproximam, formando uma Célula Integradora de Ensino. Assim, a Sociologia Aplicada, com um total de 34 horas-aula, é oferecida no segundo ano, no módulo de saúde coletiva que inclui mais três disciplinas: Antropologia Aplicada 34 horas-aula, Psicologia Aplicada 17 horas-aula, e Epidemiologia 17 horas-aula. As quatro disciplinas perfazem um total de 102 horas aula, resultando em uma única nota final e sendo ministradas a partir de uma única ementa, assim definida "Noções Gerais de Sociologia, Antropologia, Psicologia e Epidemiologia aplicadas à Saúde para a atuação em equipe multiprofissional de saúde" (UEM, 2010). Já, os objetivos são fracionados por disciplina.

Vale ressaltar que as disciplinas do módulo Saúde Coletiva são ministradas por professores com formação na área das disciplinas e vinculados em seus respectivos departamentos ${ }^{16}$. Considerar que as quatro disciplinas perfazem um total de 102 horas-aula é constatar que a carga horária ainda é muito reduzida e contradiz o discurso legal e formal, que enfatiza a necessidade de uma formação humanística voltada a aprofundar os determinantes sociais, ambientais, afetivos e culturais, que envolvem o processo saúde-doença, aplicado à Odontologia, em uma perspectiva crítica, reflexiva, ética e cidadã, segundo as orientações legais para os cursos de Ensino Superior.

O conteúdo programático do Plano de Ensino, ministrado na disciplina de Sociologia Aplicada ${ }^{17}$, no ano de 2016, está em consonância com a proposta do PPC de Odontologia e com a ementa da disciplina, como se observa no quadro a seguir.

Quadro 1 - Conteúdos lecionados na disciplina de Sociologia Aplicada ${ }^{18}$

\section{CONTEÚDO PROGRAMÁTICO DA DISCIPLINA}

A Sociologia como ciência e os principais fundadores

Relação Sociologia e saúde:

Contribuição das ciências sociais para as práticas de saúde

Determinantes sociais da Saúde

Ética e profissão na perspectiva sociológica

Relações de Gênero, profissão e especializações na Odontologia

Pacientes com deficiência mental e atendimento odontológico

Odontologia e a criança

Raça, saúde e Odontologia

Etnia e saúde bucal

Representações sociais e saúde bucal

Fonte: Plano de Ensino da disciplina de Sociologia Aplicada (2016).

\footnotetext{
${ }^{15}$ As disciplinas são: Iniciação, Políticas de Saúde, Bioestatística Aplicada, Métodos em Odontologia, Sistemas em Odontologia, Epidemiologia, Antropologia Aplicada, Sociologia Aplicada, Psicologia Aplicada.

${ }^{16}$ Ciências Sociais, Psicologia, Epidemiologia.

${ }^{17}$ A disciplina foi ministrada por uma professora doutora em sociologia, vinculada ao Departamento de Ciências Sociais.

${ }^{18}$ A bibliografia utilizada para a disciplina contempla autores da área da Sociologia Clássica, Sociologia da Saúde e Saúde Coletiva.
} 
Vale reforçar que a metodologia e a didática assumidas pela professora, no aprofundamento dos conteúdos sociológicos, não são instrumentos neutros, pois também interferem na produção de sentidos, uma vez que a interação dos/as estudantes com os conteúdos sociológicos ocorre por meio de uma relação intersubjetiva com a professora, cuja relação pode interferir nos sentidos produzidos. Por outro lado, os/as estudantes são os enunciadores da ação narrativa e expõem os significados construídos em uma relação experiencial e reflexiva com os temas debatidos em sala de aula. Ao adotar a perspectiva hermenêutica de compreensão, damos prioridade aos sentidos expressos pelos estudantes, que são sujeitos da reflexão que produzem na sua interação com os conteúdos sociológicos, como bem pontuamos nos pressupostos metodológicos. Nesse sentido, a contribuição da teoria feminista também tem sido valiosa, para desmitificar a pura objetividade e universalidade do conhecimento, mostrando que ele é sempre situado e subjetivo, já que "nenhum trabalho teórico está distante da experiência de quem o escreve." (ALCOFF, 1999, p. 125).

Após contextualizar a Sociologia na grade curricular do Curso de Graduação em Odontologia e evidenciar os conteúdos ministrados na disciplina de Sociologia Aplicada, torna-se significativo fazer ecoar a voz daqueles que são os destinatários do ensino, nesse caso, os/as estudantes de Odontologia, para evidenciar como eles avaliam a contribuição da Sociologia para a sua carreira profissional e analisar se esses sentidos se aproximam das orientações legais e das competências da disciplina de Sociologia no Ensino Superior, em um curso voltado para a saúde.

\section{IMPORTÂNCIA E SENTIDOS DO ENSINO DE SOCIOLOGIA NA VISÃO DOS ESTUDANTES DE ODONTOLOGIA}

As narrativas dos/as estudantes de Odontologia expõem sua reflexão pessoal sobre a importância e a contribuição da disciplina de Sociologia para a formação profissional. Suas narrativas são pautadas por uma consciência reflexiva que é característica de toda a ação humana na modernidade, como bem ressaltou o sociólogo Anthony Giddens (2002). Assim, elas expressam os sentidos produzidos pela experiência vivenciada de estudo, debate e reflexão dos conteúdos aprofundados durante a disciplina de Sociologia.

Para facilitar a análise recortamos as narrativas reflexivas por categorias temáticas e as agrupamos em 16 unidades de sentidos, de modo que fosse possível verificar as incidências em relação à importância que os/as estudantes atribuíram à disciplina da Sociologia para sua vida e formação profissional. Em uma primeira análise, relacionamos os núcleos de sentido com as competências do ensino da Sociologia, com as DCNs e com o PPC do Curso de Odontologia, conforme se visualiza no Quadro 2.

Quadro 2- Unidades de sentido sobre a importância da Sociologia na formação de profissionais de Odontologia, incidências e sua relação com as competências da Sociologia e com os documentos legais ${ }^{19}$

\begin{tabular}{|cl|c|c|}
\hline \multicolumn{1}{|c|}{ Unidades de sentido } & Incidências & Relação com... \\
\hline 1. & Proporciona maior conhecimento da realidade social e cultural. & 02 & $\begin{array}{c}\text { Sociologia geral } \\
\text { DCNs }\end{array}$ \\
\hline 2. & $\begin{array}{l}\text { Prepara o profissional para o pensamento crítico e reflexivo sobre a } \\
\text { realidade social. }\end{array}$ & 14 & $\begin{array}{c}\text { Sociologia Geral } \\
\text { DCNs } \\
\text { Aulas ministradas }\end{array}$ \\
\hline 3. & Promove uma formação para a cidadania. & 03 & $\begin{array}{c}\text { Sociologia geral } \\
\text { DCNs }\end{array}$ \\
\hline 4. & $\begin{array}{l}\text { Permite sair do puro tecnicismo e construir um olhar mais } \\
\text { humanizado na relação com os pacientes. }\end{array}$ & 14 & $\begin{array}{c}\text { Sociologia da Saúde } \\
\text { DCNs PPC }\end{array}$ \\
\hline 5. & Proporciona uma formação generalista, ética, humanista e reflexiva. & 07 & $\begin{array}{c}\text { DCNs } \\
\text { PPC }\end{array}$ \\
\hline
\end{tabular}

\footnotetext{
${ }^{19}$ Convém deixar claro, que optamos pelas incidências dos sentidos produzidos e não por número de estudantes, porque suas narrativas incluíam diferentes núcleos de sentidos. Essa escolha tem a ver com o objetivo deste artigo, que não é produzir um estudo de dados quantitativos, mas evidenciar a produção dos sentidos subjetivos e a sua relação com os discursos formais e legais sobre a competência da Sociologia.
} 


\begin{tabular}{|c|c|c|c|}
\hline 6. & $\begin{array}{l}\text { Promove uma visão global do processo saúde-doença e a sua } \\
\text { relação com os fatores ambientais, sociais, políticos .... modelo } \\
\text { biopsicossocial. }\end{array}$ & 10 & $\begin{array}{c}\text { Sociologia da Saúde } \\
\text { DCNs Aulas ministradas }\end{array}$ \\
\hline 7. & Constrói uma visão interdisciplinar do processo saúde-doença. \\
\hline 8. & $\begin{array}{l}\text { Permite compreender a saúde como um fenômeno social, resultado } \\
\text { das interações humanas. }\end{array}$ & 04 & Sociologia da saúde \\
\hline 9. & $\begin{array}{l}\text { Ajuda na compreensão do indivíduo não apenas como um ser } \\
\text { biológico, mas social. }\end{array}$ & 04 & $\begin{array}{c}\text { Sociologia da Saúde } \\
\text { Aulas ministradas }\end{array}$ \\
\hline 10. & $\begin{array}{l}\text { Proporciona maior sensibilização em relação ao tratamento de } \\
\text { pessoas com deficiências mentais e o compromisso do profissional } \\
\text { para denunciar casos de maus tratos e violência contra crianças. }\end{array}$ & 11 & Aulas ministradas \\
\hline 11. & $\begin{array}{l}\text { Reforça a importância de assumir uma conduta ética na profissão. } \\
\text { ministradas }\end{array}$ \\
\hline 12. & $\begin{array}{l}\text { Reforça a importância de um trabalho multiprofissional e } \\
\text { interdisciplinar na saúde. }\end{array}$ & 07 & $\begin{array}{c}\text { DCNs - PPC } \\
\text { Aulas ministradas }\end{array}$ \\
\hline 13. & $\begin{array}{l}\text { Faz perceber que é necessário ampliar os conteúdos de perspectiva } \\
\text { humana e social para a formação de profissionais da saúde. }\end{array}$ & 04 \\
\hline 14. & $\begin{array}{l}\text { Contribui para desconstruir preconceitos sociais e respeitar as } \\
\text { diferenças. }\end{array}$ & 04 & $\begin{array}{c}\text { Percepção dos estudantes } \\
\text { em relação à proposta } \\
\text { pedagógica do curso }\end{array}$ \\
\hline 15. & $\begin{array}{l}\text { Ajuda a tomar consciência do papel social da Odontologia. } \\
\text { Aulas ministradas }\end{array}$ \\
\hline 16. & $\begin{array}{l}\text { Permite refletir sobre novos temas sociais como a questão de } \\
\text { gênero e raça, na sua relação com a Odontologia. }\end{array}$ & 12 & $\begin{array}{c}\text { Percepção dos estudantes } \\
\text { a partir das Aulas } \\
\text { ministradas }\end{array}$ \\
\hline
\end{tabular}

Fonte: Pesquisa de campo (2016).

Observa-se, no Quadro 2, que os sentidos que os estudantes atribuem à Sociologia, de modo geral, contemplam as especificidades da Sociologia defendidas por Giddens (1984), Oliveira e Costa (2007) e Lahire (2014), como já mencionamos neste trabalho. Assim, esses sentidos ora se relacionam com as competências da Sociologia geral, ora com a Sociologia aplicada à saúde, e outras vezes com os aspectos legais do Curso de Odontologia (DCN e PCC) e com os conteúdos trabalhados na disciplina. Embora nem todos os estudantes apontem os mesmos sentidos, porque isso depende de uma construção subjetiva, que ocorre por meio da interação com os conteúdos aprofundados, é possível constatar que há uma relação coerente entre a formação sociológica e o que se espera do profissional egresso. Por outro lado, mesmo que os sentidos atribuídos à importância da disciplina de Sociologia apontem essa conexão com os discursos legais e formais, não se pode interpretar que os estudantes estejam fazendo uma mera reprodução de tais discursos, isso porque eles/as não falam de maneira abstrata sobre o conhecimento que a disciplina proporciona, mas da experiência vivenciada em sala de aula, a partir do debate, do estudo, da reflexão, de modo que as relações que estabelecem com os discursos legais e formais do curso e sobre as demais disciplinas, que estão na matriz curricular de sua formação profissional, começam a produzir sentido em suas vidas e para o exercício da profissão.

Olhando por dentro das narrativas observa-se que, ao fazer esse processo, os/as estudantes não somente internalizam valores e desenvolvem as competências e habilidades que são esperadas para o exercício de sua profissão, mas são levados, de maneira reflexiva, a criar consciência de sua responsabilidade ética, profissional e social. Isso nos faz corroborar com o sociólogo francês Vicente de Gaulejac (2004/2005), que os discentes, aqui, aparecem como sujeitos não apenas de uma ação narrativa, mas imbuídos de reflexividade que vai além do pensamento e se manifesta na capacidade criativa de relacionar, de se projetar como profissionais e de querer fazer algo pela sociedade, embasados no conhecimento adquirido. Transcrevemos algumas narrativas que mostram como esses sentidos se conectam na vida dos discentes ${ }^{20}$ :

\footnotetext{
${ }^{20}$ Nas narrativas selecionadas como representativas de uma dada temática, utilizamos nomes fictícios para os/as estudantes, de acordo com os princípios éticos que regem as ações de pesquisa. Além disso, registramos as manifestações como estavam escritas no material coletado, isto é, sem preocupação com a correção ortográfica ou gramatical.

Educação em Revista|Belo Horizonte|v.36|e219614|2020
} 
Aprendemos com essa disciplina questões que jamais seriam ensinadas em disciplinas específicas da Odontologia, que nos ensinam técnicas a serem realizadas nos pacientes. Portanto, a Sociologia trouxe aprendizados de grande valia para a nossa formação. Com as discussões realizadas em sala, refletimos sobre o nosso verdadeiro papel perante a sociedade e a necessidade de nos tornarmos futuros profissionais mais conscientes sobre os diversos problemas que rodeiam nossos pacientes e que jamais seriam pensados se houvesse somente o aprendizado da técnica (Tauane).

A Sociologia trouxe para nós, uma visão da Odontologia que parte de um outro ponto de vista, que não seja o técnico, o teórico, o particular, o consultório, o lucro, mas sim, de uma visão social, humanizada, caridosa, um olhar bondoso para o próximo, de compaixão, de se colocar no lugar do seu paciente, de respeitar suas limitações e seus direitos. Essa visão faz nos construir um profissional que exerce com importância o seu papel na sociedade (Tainá).

Ter uma matéria com caráter teórico-reflexivo é de extrema importância para nos lembrar que antes de sermos bons técnicos, devemos ser bons humanos, no tratamento de nossos pacientes (Neusa).

Com essa disciplina, sem esquecer da antropologia e da psicologia, vimos como é importante esse olhar social na nossa graduação, em meio a tanto aprendizado técnico e clínico, se faz necessário um olhar social e humanizado, pois trabalharemos com pessoas, que se submetem aos nossos cuidados, aprendidos na graduação (Talya).

Observamos que o relato de Talya inclui também as outras disciplinas que estão integradas no mesmo módulo de saúde coletiva, o que reforça a importância das disciplinas de humanidades na formação acadêmica de profissionais técnicos. As quatro narrativas, de maneira distinta, apresentam um discurso que se aproxima das orientações das DCNs e do PPC do Curso de Odontologia. Contudo, agora, as estudantes fazem a experiência com os conteúdos da Sociologia, que não são mais abstratos ou pura normatização distante, mas passam a ter um sentido e são avaliados como importantes por fazer a diferença na formação profissional e por agregar outros valores, que vão além do saber técnico, necessário à profissão. Como já enfatizamos, nas narrativas, está claramente exposta a ideia de que o ensino da Sociologia permite despertar a consciência de sujeito, de profissionais conscientes da realidade e que têm um papel social a desempenhar.

Como se observa no Quadro 02, 14 narrativas reforçam a importância do ensino da Sociologia para a construção de um olhar menos tecnicista e mais humanizado nos profissionais. Embora isso pareça ser pouco relevante em uma turma de 38 estudantes de um curso de formação técnica, esse número já é positivo porque mostra que a Sociologia e as demais disciplinas que integram o módulo da saúde coletiva são fundamentais para formar um profissional, que não seja somente um técnico, mas uma pessoa humanizada, com um olhar mais ampliado em relação à realidade social e aos fatores determinantes da saúde-doença. Nessa mesma direção, um estudo realizado na UFSC, em 2017, apontou que os professores que lecionavam Sociologia, em diferentes cursos de graduação, valorizavam a presença dessa disciplina "por representar uma formação humanística, em contraponto ao tecnicismo crescente e hegemônico na educação.” (BRUNETTA; AMARAL, 2017).

Essa sobrevalorização do tecnicismo na profissão do cirurgião-dentista não é apenas um olhar desde dentro, ou seja, dos estudantes, mas também das pessoas que acessam ao serviço especializado de saúde bucal, como aparece na narrativa de Gisele, o que certamente merece ser problematizado na estrutura curricular da formação dos profissionais.

Diante do tecnicismo que é produzido e reproduzido no ambulatório-escola e de pouca "sensibilidade social" presente em muitos cirurgiões-dentistas, que comumente se ouve da população, a Sociologia se mostra tão importante para as áreas da saúde, uma vez que o profissional deve saber lidar não apenas com os fatos/técnica, mas sim com a parte social e conhecer as condições psíquicas e sociais do paciente é indispensável. (Gisele).

Ao se contrapor ao tecnicismo, Gisele reforça a visão de um ser humano com diferentes dimensões que precisam ser consideradas no atendimento médico. Não um corpo somente físico, ou um aglomerado de órgãos que precisam ser tratados. Essa visão, em parte, vem da contribuição das Ciências 
Sociais para o campo da saúde, na qual o corpo passa a ser visto em relação com a dimensão social, ambiental e afetiva; que adoece ou não de acordo com essas relações, nas quais está implicado.

De acordo com Quadro 02, outro ponto de maior incidência no conteúdo das narrativas dos/as estudantes é justamente uma competência específica da disciplina de Sociologia, ou seja, o desenvolvimento do pensamento crítico e reflexivo a respeito da realidade social, como aparece bem colocado na narrativa da estudante Diones: "a Sociologia aplicada à área da saúde é de extrema importância para a formação dos graduandos, contribuindo para que se tornem profissionais mais críticos, reflexivos acerca da realidade social, em que estão inseridos." Tal concepção, tem sido defendida por Giddens (1984) e Lahire (2014), como um dos principais papéis da disciplina de Sociologia, sobretudo, porque desencadeia uma formação racional sobre os fenômenos sociais ou de um conhecimento científico da realidade social, o que justifica sua importância nos programas educacionais.

Nessa mesma direção, a estudante Jeane não somente reforça o pensamento crítico, mas também outro aspecto de competência da Sociologia, que é o de oferecer uma visão mais ampla da realidade social:

A Sociologia contribui diretamente no desenvolvimento das futuras e atuais relações do graduando com seus pacientes e até mesmo colegas, pois ela forma o pensamento crítico, fazendo com que ele saia do senso comum e desenvolva uma visão mais ampliada da realidade social, em que está inserido ou atuando (Jeane).

Para alguns estudantes, a Sociologia Aplicada contribui para "proporcionar uma formação generalista, ética, humanista e reflexiva." $\mathrm{Na}$ verdade, eles/as estão fazendo uma conexão com o perfil que se espera do profissional/egresso do Curso de Odontologia, conforme propõe as DCNs e o PPC do curso. Isso evidencia que esses estudantes são sujeitos reflexivos, no sentido proposto por Giddens (2002), porque interpretam discursivamente a natureza e as razões da ação de estudar, na sua relação com o perfil a ser incorpororado, que passa a fazer parte de sua identidade profissional. É uma espécie de monitoramento de si, pois quanto "mais o indivíduo forja reflexivamente sua auto-identidade, mais ele se torna consciente de que as práticas recorrentes moldam os resultados do seu futuro." (GIDDENS, 2002, p. 75).

Outro aspecto a ser ressaltado é o fato de os estudantes citarem que a Sociologia tem sido importante porque permite compreender o conceito de saúde de forma mais ampla. Aqui eles/as estabelecem uma relação direta com o conceito assumido pela Organização Mundial de Saúde (OMS), "como um bem-estar físico, psíquico e social." Tal concepção está em consonância com a literatura das Ciências Sociais da Saúde, que tem dado uma contribuição significativa para pensar o processo o saúdedoença para além do modelo biomédico, ou seja, como resultado dos determinantes sociais. Essa ideia parece relevante, uma vez que 10 estudantes atribuem importância à Sociologia para a formação profissional do cirurgião-dentista, nessa perspectiva.

Como sabemos, a preparação para o exercício da cidadania comumente tem sido atribuída à Sociologia. Contudo, constatamos que somente três estudantes mencionaram isso, mas sem aprofundar o que implicaria, de fato, o exercício da cidadania, como aparece no relato de Marlene: "A Sociologia foi de extrema importância para minha formação profissional, visto que contribuiu para o meu crescimento como cidadã e futura cirurgiã-dentista." Outra estudante relaciona o ser cidadã com o compromisso de denunciar os maus-tratos percebidos em pacientes que são crianças ou com a inserção em projetos sociais, que visam levar saúde a pacientes com necessidades especiais, idosos, pobres. Em outros momentos, o exercer a cidadania aparece nas entrelinhas do que os/as estudantes entendem por exercer o papel social da Odontologia, citado por 12 estudantes.

Embora tais práticas sejam importantes, nota-se a necessidade de um aprofundamento do que implica, de fato, o exercício da cidadania na vida social. Certamente, essa pouca referência sobre a competência da formação para cidadania, atribuída à Sociologia, ou entendida, não de maneira crítica, como qualquer prática social, seja evidência de uma ausência de definição e problematização desse conceito nos documentos legais, como bem apontou o estudo de Brunetta e Amaral (2017).

Nesse sentido, Lahire (2014) menciona que os Estados, em toda parte do mundo, enfatizam a necessidade de formar para a cidadania, e buscam, em geral, responder a essa exigência pelo ensino moral ou da educação cívica. Contudo, para o autor, 
as ciências do mundo social poderiam e até mesmo deveriam estar no centro dessa formação: o relativismo antropológico (que não tem nada a ver com um indiferentismo ético), a tomada de consciência da existência de uma multiplicidade de "pontos de vista" ligada às diferenças sociais, culturais, geográficas, etc., o conhecimento de certos "mecanismos" e processos sociais etc., tudo isso poderia utilmente contribuir para formar cidadãos que seriam um pouco mais sujeitos de suas ações em um mundo social desnaturalizado, um pouco menos opaco, um pouco menos estranho e um pouco menos indomável. (LAHIRE, 2014, p. 59).

$\mathrm{Na}$ dimensão das diferenças sociais e culturais que, de certa maneira tem a ver com cidadania e inclusão democrática, convém destacar um aspecto que nos parece distinto, isso porque, em alguns conteúdos das narrativas, a disciplina de Sociologia aparece como relevante porque possibilitou debater sobre temas que são importantes para a formação profissional e que, certamente, não seriam tratados em outras disciplinas, como ilustram as duas narrativas a seguir.

A matéria de Sociologia foi de grande importância para minha formação acadêmica, já que nela, foram tratadas de assuntos que provavelmente não verei em outras matérias, e são fundamentais para meu dia a dia da clínica, já que lidamos principalmente com pacientes mais carentes, os quais possuem um histórico familiar normalmente, complexo. (Marilei).

Depois de concluir a disciplina de Sociologia, considero que esta matéria é de suma importância para o curso de Odontologia e consequentemente para a formação do profissional da saúde, haja vista que, foram abordados temas que geralmente não são discutidos em outras disciplinas do curso. (Marlene).

Esses outros temas importantes, mencionados de maneira geral pelas estudantes, tratam-se dos conteúdos que abordam as questões sociais da contemporaneidade, como gênero, raça, deficiências mentais e violência contra crianças, na sua relação com a Odontologia, temas que foram debatidos em sala de aula. Nesse sentido, de acordo com o Quadro 02, 11 estudantes mencionaram que a Sociologia foi significativa para as suas vidas e formação profissional, porque fez suscitar um novo valor, como parte de uma identidade ética e profissional ou de um sujeito que tem uma responsabilidade com as causas sociais, com os direitos humanos e com os valores democráticos. Ou seja, proporcionou maior sensibilização em relação ao tratamento de pessoas com deficiências mentais e o compromisso do profissional para denunciar casos de maus tratos e violência contra crianças.

Observa-se como conteúdos sociológicos como parte do currículo têm potencial na formação de identidades profissionais comprometidas com os direitos humanos e valores democráticos. Nessa perspectiva, Lahire (2014) tem defendido a importância da Sociologia para o fortalecimento da democracia moderna e para tomada de consciência em relação às diferenças sociais, como uma ferramenta de desnaturalização do mundo social e de formação de cidadãos sujeitos de suas ações.

Finalmente, podemos afirmar que esses relatos reflexivos enunciados pelos/as estudantes de Odontologia podem ser vistos como uma fotografia do olhar que eles têm sobre a disciplina de Sociologia, e do sentido construído para a sua formação profissional, a partir de uma relação interativa e reflexiva com os conteúdos da disciplina. Trata-se de um olhar positivo oposto à forma como a Sociologia e outras disciplinas das humanidades, em geral, são vistas em muitos cursos técnicos, isto é, como um adendo, uma disciplina que está na estrutura curricular apenas para cumprir questões legais. Isso ocorre, em parte, pela sobrevalorização de uma educação mais voltada para o mercado, que se adequa aos interesses do Banco Mundial, de modo que as Ciências Sociais e Humanas estão, praticamente, na base da hierarquia quando está em jogo o montante de recursos que são destinados para pesquisas.

\section{CONSIDERAÇÕES FINAIS}

Neste trabalho procuramos adentrar no debate sobre a relevância do ensino de Sociologia na formação em nível superior, tomando por base narrativas sobre os sentidos da disciplina de Sociologia na formação profissional enunciadas por estudantes do curso de Odontologia. 
Os sentidos são diversos e apontam potencialidades para a construção de um novo olhar sobre o que é ser um profissional da saúde, na sua relação com dimensão social e cultural. Destacamos, aqui, alguns dos sentidos que foram atribuídos pelos/as estudantes sobre a importância do ensino da Sociologia. Na visão dos discentes, ela potencializou: uma nova visão da realidade social; a formação de um pensamento crítico e reflexivo; a ética profissional; o olhar humanizado para com os pacientes; a importância do trabalho interdisciplinar e multiprofissional; a desconstrução de preconceitos e o respeito para com as diferenças; a visão ampliada do processo saúde-doença; o contato com novos temas sociais - gênero e raça; entre outros. Essa variedade de sentidos mostra a relevância da disciplina de Sociologia na educação profissional.

Os estudantes atribuem sentidos que se conectam com o papel específico da Sociologia, com as competências a serem desenvolvidas pela disciplina e com as questões legais e formais do curso. Essas narrativas não se configuram como reprodução de discursos normativos, porque aparecem como expressões de sentido produzidas por estudantes que se constituem sujeitos de suas narrativas. Eles não estão falando de um conhecimento abstrato, mas a partir de um contexto situado, da experiência vivenciada em relação aos temas estudados, refletidos e debatidos em sala de aula, em que o conteúdo sociológico passa a produzir sentido para as suas vidas e para o exercício da profissão. Trata-se, também, de sujeitos reflexivos que têm consciência do perfil que é esperado para os profissionais da saúde bucal, de modo que os valores despertados pela disciplina podem, facilmente, ser relacionados com as questões legais e formais do processo de formação profissional.

Não se pode negar que, nas áreas da saúde, diferentemente de outras áreas técnicas, a Sociologia, assim como as demais Ciências Sociais, seja avaliada como importante. Isso porque já existe um discurso interdisciplinar que perpassa os Projetos Pedagógicos dos Cursos. Pode-se afirmar que a importância da Sociologia para a Odontologia tem respaldo nas práticas e discursos que dão sustentação ao Sistema Único de Saúde. Essa política de saúde pública tem difundido a concepção do "conceito ampliado de saúde", por meio da implantação do Programa de Saúde da Família, pautado em valores, como prevenção, promoção, equidade, humanização, entre outros. Esse modelo sugere um profissional que não seja somente tecnicista, mas que tenha uma visão humanista, capaz de compreender o processo saúde-doença como resultado de fatores sociais, culturais, políticos, econômicos, afetivos e ambientais. Tais questões, certamente, têm relação direta com a importância que os estudantes atribuem à disciplina de Sociologia na sua formação, como evidenciamos neste estudo.

Paradoxalmente, por mais que os discursos legais e formais em torno da formação do profissional de Odontologia enfatizem a necessidade de formar um cirurgião-dentista com perfil generalista, ético, humanista e reflexivo, a estrutura curricular do curso ainda aparece centrada na formação tecnicista, com poucas disciplinas voltadas à formação humanista, social e cultural e, muitas vezes, presentes somente nos primeiros anos do curso. Talvez esse seja um desafio a ser pensado nos cursos de graduação em Odontologia, uma vez que as Ciências Sociais (Antropologia e Sociologia) são vistas como disciplinas importantes nos discursos legais e formais do curso e também na visão dos estudantes. Contudo, a elas é destinada uma carga horária reduzida, como evidenciamos neste estudo. Pergunta-se: é possível desenvolver importantes competências na formação profissional com poucas horas que se reservam a tais disciplinas? Ao reconhecer a importância da Sociologia, os próprios estudantes, em suas narrativas, apontaram ser necessário "ampliar conteúdos de perspectiva humana e social na formação de profissionais da saúde." Certamente, isso vale também para Epidemiologia e Psicologia Social que apresentam carga horária bem mais reduzida.

Se a contribuição da Sociologia é importante para uma formação profissional que não esteja somente voltada ao tecnicismo e aos interesses de mercado, mas à formação de cidadãos humanistas e sensíveis em relação às questões sociais, então a Sociologia ou as Ciências Sociais precisam ser mais valorizadas no conjunto das disciplinas. Ao olharmos para a reforma do Ensino Médio parece que estamos em um movimento contrário, porque essas disciplinas são tratadas como saberes não tão importantes e "úteis". Certamente, hoje, mais do que nunca, é necessário que a educação superior prepare os jovens não somente para o mercado de trabalho, mas para o pensamento científico reflexivo e crítico e para o exercício da cidadania; questão que continua sendo um desafio e algo tão necessário, em tempos em que os processos democráticos parecem estar perdendo força. 
Ressaltamos, aqui, que a Conferência Mundial sobre Educação Superior atribui ao ensino superior a missão de contribuir com o desenvolvimento sustentável e o melhoramento da sociedade como um todo, formando pessoas altamente qualificadas, cidadãs e cidadãos responsáveis que se tornam capazes de atender às necessidades de todos os aspectos da atividade humana. E, sem dúvida, a Sociologia é imprescindível nesse processo, como este estudo pôde evidenciar, a partir das narrativas de estudantes de Odontologia da UEM.

Diante disso, pode-se afirmar que este trabalho traz uma contribuição específica para o rol dos estudos sobre o ensino de Sociologia na Educação Superior, sobretudo, por se referir à formação profissional em um curso da área de saúde, no qual o saber técnico é predominante. Ao mesmo tempo, apresenta um olhar positivo sobre a importância das Ciências Humanas e Sociais para a formação profissional, questão esta que se opõe aos discursos rasos e infundados que estão sendo reiterados no atual contexto político, que visam desqualificar o papel dessas ciências na formação acadêmica, com o intuito de assegurar uma formação de profissionais despolitizados, acríticos, individualistas e úteis ao mercado neoliberal. Assim, concluímos este trabalho com um pensamento de Lahire, que parece fazer sentido no atual momento histórico que estamos vivendo.

Filhas da democracia, as Ciências Sociais - obviamente mal vistas pelos regimes conservadores e erradicadas pelos regimes ditatoriais - servem a democracia e são preocupantes. Porque a democracia partiu ligada, na história, com as "Luzes" (les Lumières) e, notadamente, com a produção de "verdades sobre o mundo social": verdade dos fatos objetiváveis, mensuráveis, que é infelizmente a verdade das desigualdades, das dominações, das opressões, das explorações, das humilhações [...] (LAHIRE, 2014, p. 50).

Lahire argumenta que sem a contribuição dessas ciências, sobretudo na educação, os cidadãos ficam desprovidos de ferramentas analíticas e críticas diante dos diferentes mecanismos difusores de ideologias que reproduzem os interesses das elites conservadoras e ocultam certas dinâmicas sociais. Nesse contexto, torna-se "imprescindível transmitir, o mais racionalmente possível e para o maior número de pessoas, os meios de decifrar e de contestar os discursos de ilusão sobre o mundo social" (LAHIRE, 2014, p. 50), no intuito de construir um mundo mais humanizado, plural e ético, como apontam os resultados deste estudo. Isso justifica a importância da Sociologia na grade curricular dos cursos profissionais, porque se trata de uma ciência crítica e humanizadora, o que também responde a uma pergunta sempre frequente: "para que serve o ensino de Sociologia?"

\section{REFERÊNCIAS}

ALCOFF, Linda. Merleau-Ponty y la teoría feminista sobre la experiencia. MORA: Revista del Instituto Interdisciplinario de Estudios de Género, Facultad de Filosofía y Letras, Buenos Aires, n. 5, p. 122-138, 1999.

APPLE, Michael W. Conhecimento Oficial: a educação democrática numa era conservadora. Petrópolis: Vozes, 1997.

BARROS MIOTTO, Mariana M. de; MARCELO, Ludmila A. Contribuição das Ciências Sociais nas práticas de Saúde Pública. Revista Brasileira de Pesquisa em Saúde, v. 11, n. 2, p. 43-48, 2009.

BARROS, Nelson F.; NUNES Everardo D. Sociologia, medicina e a construção da Sociologia da saúde, Rev. Saúde Pública, v. 43, v. 1, p. 169-175, 2009.

BRASIL. MEC. Parecer CNE/CES n 777/1997 de 3 de fevereiro de 1997. Orientações para as Diretrizes Curriculares dos cursos de graduação. Disponível em: <http://portal.mec.gov.br/cne/arquivos/pdf/CES0776.pdf>. Acesso em: 13 mar. 2018.

BRASIL. MEC. Resolução CNE/CES 3, de 19 de fevereiro de 2002. Diretrizes Curriculares Nacionais do Curso de Graduação em Odontologia. Disponível em: <http://portal.mec.gov.br/cne/arquivos/pdf/CES032002.pdf>. Acesso em: 13 mar. 2018. 
BRUNETTA, Antônio A.; AMARAL Letícia H. do. Potencialidades do Ensino de Sociologia para o desenvolvimento da formação profissional em Cursos de Graduação da Universidade Federal de Santa Catarina. Revista desenvolvimento, fronteiras e cidadania, v. 1, n. 1, p. 56-79, jul. 2017.

FERNANDES, Florestan. As ciências sociais no Brasil. Petrópolis: Vozes, 1977.

GAULEJAC, Vicente de. O âmago da discussão: sociologia do indivíduo à sociologia do sujeito. Cronos, Natal, v. 5-6, n. 1-2, p. 59-77, jan./dez. 2004-2005.

GIDDENS, Anthony. Modernidade e Identidade. Rio de Janeiro: Jorge Zahar Editor, 2002.

GIDDENS, Anthony. Sociologia: uma breve porém crítica introdução. Rio de Janeiro: Zahar Editores, 1984.

IANNI, Otávio. A Sociologia numa época de globalismo. In: FERREIRA, Leila da Costa (org.). A Sociologia no horizonte do século XXI. São Paulo: Bontempo, 1999.

JINKINS, Nise. Ensino de sociologia: particularidades e desafios contemporâneos. Mediações. Londrina, v. 12, n. 1. jan./jun. 2007.

LAHIRE, Bernard. Viver e interpretar o mundo social: para que serve o ensino da Sociologia? Revista de Ciências Sociais, Fortaleza, v. 45, n. 1, p. 45-61, jan./jun. 2014.

MARTINS, Paulo H; FONTES, Breno. A sociologia e a saúde: caminhos cruzados. Recife: Redes Sociais e Saúde, 2008.

MATOS, Izabella Barison et al. Profissões e Ocupações de Saúde e o Processo de Feminização: Tendências e Implicações. Athenea Digital - Revista de pensamento e investigação social, v. 13, n. 2, p. 239-244, jul. 2013.

MINAYO, Maria Cecília de Souza de. Hermenêutica-Dialética como caminho do pensamento social. In: MINAYO, Maria Cecília de Souza de: DESLANDES, Suely FERREIRA (org.). Caminhos do pensamento epistemologia e método. Rio de Janeiro: Ed. Fiocruz, 2003. p. 83-107.

MINAYO, Maria Cecília de Souza de. O desafio do conbecimento: pesquisa qualitativa em saúde. São Paulo: Hucitec-Abrasco, 2000.

OLIVEIRA, Luiz Fernandes de; COSTA, Ricardo Cesar Rocha da. Sociologia para Jovens do Século XXI. Rio de Janeiro: Imperial Novo Milênio, 2007.

OLIVEIRA. Amurabi. Revisitando a história do ensino de Sociologia na Educação Básica. Acta Scientiarum. Education, Maringá, v. 35, n. 2, p. 179-189, 2013.

OLIVEIRA, Terezinha. Planejamento, projeto político pedagógico e organização curricular do ensino. Maringá, 2012. Apostila produzida para NEAD - Núcleo de Educação a Distância do Centro Universitário de Maringá.

PESHKIN, Alan. The goodness of qualitative research. Educational Researcher, v. 22, n. 2, p. 23-29, mar. 1993.

REGO, Virginia Vilas Boas Sá. Sociologia e Ensino Superior: novos rumos?!. In: CONGRESSO BRASILEIRO DE SOCIOLOGIA 22, 2005, Belo Horizonte, Anais [...]. SBS - Sociedade Brasileira de Sociologia: São 2005.2 Paulo, Disponível em: 
$<$ http://www.sbsociologia.com.br/portal/index.php?option=com_docman\&task=doc_download\&gid $=1218 \&$ Itemid=170>. Acesso em: 10 mar. 2018 .

UNESCO. Declaração Mundial sobre Educação Superior no Século XXI: Visão e Ação Documento da Conferência Mundial sobre Educação Superior, 1998. Disponível em: $<$ http://www.direitoshumanos.usp.br/index.php/Direito-a-Educa\%C3\%A7\%C3\%A3o/declaracaomundial-sobre-educacao-superior-no-seculo-xxi-visao-e-acao.html>. Acesso em: 13 mar. 2018.

UEM. Guia do estudante do curso de odontologia. Departamento de Odontologia. Maringá: Clichetec, 2010.

UEM. Plano de ensino da disciplina de Sociologia. Maringá: Resolução, no 195/2005-CEP. 2016.

Submetido: 06/02/2019

Aprovado: 05/11/2019 